portant results. In a recent communication (Astronomische Nachrichten, No. 2983), the orbits of Mimas and Enceladus, and their relation to those of the other satellites, are considered. The orbit of Mimas has an eccentricity of $0^{\circ} 016$, and an inclination of $1^{\circ} 26^{\prime}$. The retrograde movement of the nodes, is about $\mathbf{r}^{\circ}$ per day, and is accompanied by a direct movement of the perisaturnium point, which is almost equal to it $\left(-365^{\circ}\right.$ and $+371^{\circ}$ per year). The comparison of the Pulkova observations with those made at Washington (1882-86) indicates an acceleration of the mean motion of Mimas, which corresponds to a retardation in the mean movement of Tethys. Dr. Struve shows that the changes in the elements and mean motions of the two satellites may increase indefinitely, or vary between certain limits. The latter explanation is proved to be the correct one, and a discussion of the observations of Sir W. Herschel, Lassell, Marth, Newcomb, Asaph Hall, \&c., leads to the conclusion that the conjunctions of Enceladus and Dione occur at the perisaturnium of the former satellite or neardy so, whilst those of Mimas and Tethys oscillate $45^{\circ}$ about the point midway between the ascending nodes of their orbits on Saturn's equator, and perform this libration in about sixty-eight years.

The masses of Dione and Tethys inferred by Dr. Struve from the libration are respectively seven and eleven times smaller than those deduced from photometric comparisons with Titan. The result for Mimas is twenty-two times smaller than that furnished by photometry. It appears necessary to admit, therefore, that in the system of Saturn, as in that of Jupiter, either the intrinsic brilliancy of the satellites increases, or their density decreases, as the planet is approached. A knowledge of the masses of the four above-named satellites, determined photometrically and found by Dr. Struve, allows those of Enceladus and Rhea to be estimated with some probability. The following are the calculated and the hypothetical values in terms of the mass of Saturn : Mimas, I/I I, 500, 000; Enceladus, I/4,000,000 ; Tethys, I/767,000 ; Dione, I/528,000; Rhea, I/200,000 ; Titan, r/4700. By adopting the above hypothetical values of the masses of Enceladus and Rhea, the observed and calculated values of the secular motions of the nodes and apses are found to agree in a very satisfactory manner. The spheroidal constant of Saturn has been determined as $0^{\circ} 0258$, which differs considerably from the value 0.0223 assumed in a previous paper (Astronomische Nachrichten, No. 2946). This alteration obviates the necessity of giving the ring-system a sensible mass in the calculations.

A New Comet $(d$ I 890$)$. - A faint comet was discovered by Mr. E. E. Barnard, of the Lick Observatory, on the 6th inst. It was then situated in Capricornus.

\section{ANTARCTIC EXPLORATION.}

THE following address, on "The Objects of Antarctic Exploration," was delivered at the annual meeting of the Bankers' Institute of Australasia, at Melbourne, on Wednesday, August 27, by Mr. G. S. Griffiths, F.G.S., F.R.G.S., His Excellency the Earl of Hopetoun being in the chair.

Mr. Griffiths said,-My experience, during the four years which have elapsed since this project was first mooted in Melbourne, is that any reference to the subject is sure to be met with the query, Cui bono? What good can it do? What benefit can come from it? What is the object to be served by such an expedition?

In setting myself to the task of answering these questions, let me observe that it would indeed be strange if an unexplored region, 8,000, ooo square miles in area-twice the size of Europe - and grouped around the axis of rotation and the magnetic pole, could fail to yield to investigators some novel and valuable information. But when we notice that the circle is engirdled without by peculiar physical conditions which must be correlated to special physical conditions within, speculation is exchanged for a confident belief that an adequate reward must await the skilled explorer. The expected additions to the geography of the region are, of all the knowledge that is to be sought for there, the least valuable. Where so many of the physical features of the country-the hills, the valleys, and the drainage lines-have been buried beneath the snow of ages, a naked outline, a bare skeleton of a map, is the utmost that can be delineated. Still, even such knowledge as this has a distinct value, and as it can be acquired by the explorers as they proceed about their more important researches, its relatively small value ought not to be admitted as a complete objection to any enterprise which has other objects of importance. Our present acquaintance with the geography of the region is excessively limited. Ross just viewed the coasts of Victoria Land, between $163^{\circ} \mathrm{E}$. and $160^{\circ} \mathrm{W}$. long. ; he trod its barren strand twice, but on each occasion for a few minutes only. From the adjacent gulf he measured the heights of its volcanoes, and from its offing he sketched the walls of its icy barrier. Wilkes traced on our map a shore-line from $97^{\circ}$ E. to $167^{\circ}$ E. long., and he backed it up with a range of mountains, but he landed nowhere. Subsequently Ross sailed over the site assigned to part of this land, and hove his lead 600 fathoms deep where Wilkes had drawn a mountain. He tells us that the weather was so very clear, that had high land been within 70 miles of that position he must have seen it ("Ross's Voyage," I278). More recently Nares, in the Challenger, tested another part of Wilkes's coast-line, and with a like result; and these circumstances throw doubts upon the value of his reported discoveries. D'Urville subsequently followed a bold shore for a distance of about 300 miles from $136^{\circ} \mathrm{E}$. to $142^{\circ} \mathrm{E}$. long. ; whilst in $67^{\circ} \mathrm{S}$. lat., and between $45^{\circ} \mathrm{E}$. and $60^{\circ}$ E. long., are Enderby's and Kemp's lands. Again, there is land to the south of the Horn, which trends from $45^{\circ}$ to $75^{\circ} \mathrm{S}$. lat.. These few discontinuous coast-lines comprise all our scanty knowledge of the Antarctic land. It will be seen from these facts that the principal geographical problem awaiting solution in these regions is the interconnection of these scattered shores. The question is, Do they constitute parts of a continent, or are they, like the coasts of Greenland, portions of an archipelago, smothered under an overload of frozen snow, which conceals their insularity? Ross inclined to the latter view, and he believed that a wide channel leading towards the Pole existed between North Cape and the Balleny Islands ("Ross's Voyage," I221). This view was also held by the late Sir Wyville Thomson. A series of careful observations upon the local currents might throw some light upon these questions. Ross notes several such in his log. Off Possession Island a current, running southward, took the ships to windward (ibid., I I95). Off Coulman Island another drifted them in the same direction, at the rate of eighteen miles a day (ibid., 1204). A three-quarter knot northerly current was felt off the barrier, and may have issued from beneath some part of it. Such isolated observations are of little value, but they were multiplied, and were the currents correlated with the winds experienced, the information thus obtained might enable us to detect the existence of straits, even where the channels themselves are masked by ice-barriers.

Finally, it is calculated that the centre of the polar ice-cap must be three miles, and may be twelve miles, deep, and that, the material of this ice mountain being viscous, its base must spread out under the crushing pressure of the weight of its centre. The extrusive movement thus set up is supposed to thrust the ice cliffs off the land at the rate of a quarter of a mile per annum. These are some of the geographical questions which await settlement.

In the geology of this region we have another subject replete with interest. The lofty volcanoes of Victoria Land must present peculiar features. Nowhere else do fire and frost divide the sway so completely. Ross saw Erebus belching out Java and ashes over the snow and ice which coated its flanks. This circumstance leads us to speculate on the strata that would result from the alternate fall of snow and ashes during long periods and under a low temperature. Volcanoes are built up, as contradistinguished from other mountains, which result from elevation or erosion. They consist of débris piled round a vent. Lava and ashes surround the crater in alternate layers. But in this polar region the snowfall must be taken into account as well as the ash deposit and the lava-flow. It may be thought that any volcanic ejecta would speedily melt the snow upon which they fell, but this does not by any means necessarily follow. Volcanic ash, the most widespread and most abundant material ejected, falls comparatively cold, cakes, and then forms one of the most effective non-conductors known. When such a layer, a few inches thick, is spread over snow, even molten lava may flow over it without melting the snow beneath. This may seem to be incredible, but it has been observed to occur. In 1828 , Lyell saw on the flanks of Etna a glacier sealed up under a crust of lava. Now, the Antarctic is the region of thick-ribbed ice. All exposed surfaces are quickly covered with snow. Snowfalls, fish-falls, and lava-flows must have been heaping themselves up around the craters during unknown ages. What has 
been the result? Has the viscosity of the ice been modified by the intercalation of beds of rigid lava and of hard-set ash? Does the growing mass tend to pile up or to settle down and spread out? Is the ice wasted by evaporation, or does the ash-layer preserve it against this mode of dissipation? These interesting questions can be studied round the South Pole, and perhaps nowhere else so well.

Another question of interest, as bearing upon the location of the great Antarctic continent, which it is now certain existed in the Secondary period of geologists, is the nature of the rocks unon which the lowest of these lava-beds rest. If they can be discovered, and if they then be found to be sedimentary rocks such as slates and sandstones, or plutonic rocks such as granite, they will at once afford us some data to go upon, for the surface exposure of granite signifies that the locality has been part of a continental land sufficiently long for the weathering and removal of the many thousands of feet of sedimentary rorks which of necessity overlie crystalline rocks during their genesis; whilst the presence of sedimentary rocks implies the sometime proximity of a continent from the surfaces of which alone these sediments, as rain-wash, could have been derived.

As ancient slate rocks have already been discovered in the ice-clad South Georgias, and as the drag-nets of the Erebus and the Challenger have brought up from the beds of these icy seas fragments of sandstones, slates, and granite, as well as the typical blue mud which invariably fringes continental land, there is every reason to expect that such strata will be found.

Wherever the state of the snow will permit, the polar mountains should be searched for basaltic dykes, in the hope that masses of specular iron and nickel might be found, similar to those discovered by Nordenskiöld, at Ovifak, in North Greenland. The interest taken in these metallic masses arises from the fact that they alone, of all the rocks of the earth, resemble those masses of extra-terrestrial origin which we know as meteorites. Such bodies of unoxidized metal are unknown elsewhere in the mass, and why they are peculiar to the Arctic it is hard to say. Should similar masses be found within the Antarctic, a fresh stimulus would be given to speculation. Geologists would have to consider whether the oxidized strata of the earth's crust thin out at the poles; whether in such a case the thinning is due to severe local erosion, or to the protection against oxygen afforded to the surface of the polar regions by their ice-caps, or to what other cause. Such discoveries would add something to our knowledge of the materials of the interior of our globe and their relation to those of meteorites.

Still looking for fresh knowledge in the same direction, a series of pendulum observations should be taken at points as near as possible to the Pole. Within the Arctic circle the pendulum makes about 240 more vibrations per day than it does at the equator. The vibrations increase in number there because the force of gravity at the earth's surface is more intense in that area, and this again is believed to be due to the oblateness of that part of the earth's figure, but it might be caused by the bodily approach to the surface at the poles of the masses of dense ultra-basic rocks just referred to. Thus, pendulum experiments may reveal to us the earth's figure, and a series of such observations, recorded from such a vast and untried area, must yield important data for the physicist to work up. We should probably learn from such investigations whether the earth's figure is as much flattened at the Antarctic as it is known to be at the Arctic.

We now know that in the past the North rolar regions have enjoyed a temperate climate more than once. Abundant seams of Palæozoic coal, large deposits of fossiliferous Jurassic rocks, and extensive Eocene beds, containing the remains of evergreen and deciduous trees and flowering plants, occur far within the Arctic circle. This circumstance leads us to wonder whether the corresponding southern. latitudes have ever experienced similar climatic vicissitudes. Conclusive evidence on this point it is difficult to get, but competent biologists who have examined the floras and faunas of South Africa and Australia, of New Zealand, South America, and the isolated islets of the Southern Ocean, find features which absolutely involve the existence of an extensive Antarctic land-a land which must have been clothed with a varied vegetation, and bave been alive with heasts, birds, and insects. As it also had had its fresh-water fishes, it must have had its rivers flowing and not frost-bound, and in those circumstances we again see indications of a modified Antarctic climate. Let us briefly consider some of the evidence for the existence of this continent. We are told by Prof. Hutton, of Christchurch, that 44 per cent. of the New Zealand flora is of Antarctic origin. The Auckland, Campbell, and Macquarie Islands all support Antarctic plants, some of which appear never to have reached New Zealand. New Zealand and South America have three flowering plants in common, also two freshwater fishes, five seaweeds, three marine crustaceans, one marine mollusk, and one marine fish. Similarly New Zealand and Africa have certain common forms, and the floras and faunas of the Kerguelen, the Crozets, and the Marion Islands are almost identical, al though in each case the islands are very small, and very isolated from each other and from the rest of the world. Tristan d'Acunha has 58 species of marine Mollusca, of which number 13 are also found in South America, six or seven in New Zealand, and four in South Africa (Hutton's "Origin of New Zealand Flora and Fauna"). Temperate South America has 74 genera of plants in common with New Zealand, and II of its species are identical (Wallace's "Island Life"). Penguins of the genus Eudyptes are common to South America and Australia (Wallace, "Dist. of Animals," I 399). Three groups of fresh-water fishes are entirely confined to these two regions. Aphritis, a fresh-water genus, has one species in Tasmania and two in Patagonia. Another small group of fishes known as the Haplochitonidx inhabit Tierra del Fuegia, the Falklands, and South Australia, and are not found elsewhere, while the genus Galaxias is confined to South Temperate America, New Zealand, and Australia. Yet the lands which have these plants and animals in common are so widely separated from each other that they could not now possibly interchange their inhabitants. Certainly towards the equator they approach each other rather more, but even this fact fails to account for the present distribution, for, as Wallace has pointed out, "the heat-loving Reptilia afford hardly any indica. tions of close affinity between the two regions" of South America and Australia, "whilst the cold-enduring Amphibia and freshwater fishes offer them in abundance" (Wallace, "Dist. of Animals," I400). Thus we see that to the north interchange is prohibited by tropical heat, while it is barred to the south by a nearly shoreless circumpolar sea. Yet there must have been some means of intercommunication in the past, and it appears certain that it took the shape of a common fatherland for the varions common forms from which they spread to the northern hemisphere. As this fatherland must have been accessible from all these scattered southern lands, its size and its disposition must have been such as would serve the emigrants either as a bridge or as a series of stepping-stones. It must have been either a continent or an archipelago.

But a further and a peculiar interest attaches to this lost continent. Those who have any acquaintance with geology know that the placental Mammalia-that is, animals which are classed with such higher forms of life as apes, cats, dogs, bears, horses, and oxen-appear very abruptly with the incoming of the Tertiary period. Now, judging by analogy, it is not likely that these creatures can have been developed out of Mesozoic forms with anything like the suddenness of their apparent entrance upon the scene. For such changes they must have required a long time, and an extensive region of the earth, and it is probable that each of them had a lengthy series of progenitors, which ultimately linked it back to lower forms.

Why, then, it is constantly asked, if this was the sequence of creation, do these missing links never turn up ? In reply to this query, it was suggested by Huxley that they may have been developed in some lost continent, the boundaries of which were gradually shifted by the slow elevation of the sea margin on one side and its simultaneous slow depression upon the other, so that there has always been in existence a large dry area with its live stock. This dry spot, with its fauna and flora, like a great raft or Noah's Ark, moved with great slowness in whatever direction the great earth-undulation travelled. But to-day this area, with its fossil evidences, is a sea-bottom; and Huxley supposes that the continent, which once occupied a part of the Pacific Ocean, is now represented by Asia.

This movement of land-surface-translation eastwards eventually created a connection between this land and Africa and Europe, and if when this happened the Mammalia spread rapidly over these countries, this circumstance would account for the abruptness of their appearance there.

Now, Mr. Blanford, the President of the Geological Society of London, in his annual address, recently delivered, advances matters a stage further, for he tells us that a growing acquaintance with the biology of the world leads naturalists to a belief that the placental Mammalia, and other of the higher forms of 
terrestrial life, originated during the Mesozoic period, still further to the southwards-that is to say, in the lost Antarctic continent, for the traces of which we desire to seek.

But it almost necessarily follows that wherever the Mammalia were developed there also man had his birthplace, and if these speculations should prove to have been well founded we may have to shift the location of the Garden of Eden from the northern to the southern hemisphere.

I need hardly suggest to you that possibilities such as these must add greatly to our interest in the recovery of any traces of this mysterious region. This land appears to have sunk beneath the seas after the close of the Mesozoic. Now, the submergence of any mass of land will disturb the climatic equilibrium of that region, and the disappearance of an Antarctic continent would prove extremely potent in varying the climate of this hemisphere. For to-day the sun's rays fall on the South Polar regions to small purpose. The unstable sea absorbs the heat, and in wide and comparatively warm streams it carries off the caloric to the northern hemisphere to raise its temperature at the expense of ours. But when extensive land received those same heat rays, its rigid surfaces, so to speak, tethered their caloric in this hemisphere, and thus when there was no mobile current to steal northwards with it, warmth could accumulate and modify the climate.

Under the influences of such changes the icy mantle would be slowly rolled back towards the South Pole, and thus many plants and animals were able to live and multiply in latitudes that to-day are barren. What has undoubtedly occurred in the extreme north is equally possible in the extreme south. But if it did occur-if South Polar lands, now ice-bound. were then as prolific of life as Disco and Spitzbergen once were-then, like Spitzbergen and Disco, the unsubmerged remnants of this continent may still retain organic evidences of the fact in the shape of fossil-bearing beds, and the discovery of such deposits would confirm or confute such speculations as these. The key to the geological problem lies within the Antarctic circle, and to find it would be to recover some of the past history of the southern hemisphere. There is no reason to despair of discovering such evidence, as Dr. M'Cormack, in his account of Riss's voyage, records that portions of Victoria Land were free from snow, and therefore available for investigation; besides which their surface may still support some living forms, for they cannot be colder or bleaker than the peaks which rise out of the continental ice of North Greenland, and these, long held to be sterile, have recently disclosed the existence upon them of a rich though humble flora.

We have now to consider some important meteorological questions. If we look at the distribution of the atmo-phere around the globe we shall see that it is spread unequally. It forms a stratum which is deeper within the tropics than about the poles and over the northern than over the southern 'semisphere, so that the barometer normals fall more as we approach the Antarctic than they do when we near the Arctic. Maury, taking the known isobars as his guide, has calculated that the mean pressure at the North Pole is $29^{\prime} 1$, but that it is only 28 at the South (Maury's " Meteorology," 259). In other words, the Antarctic circle is permanently much barer of atmosphere than any other part of the globe. Again, if we consult a wind chart we shall see that both poles are marked as calm areas. Each is the dead centre of a perpetual wind vortex, but the South Polar indraught is the stronger. Polarward winds

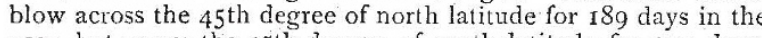
year, but across the 45 th degree of south latitude for 209 days. And while they are drawn in to the North Pole from over a disk-shaped area 5500 miles in diameter, the South Polar indraught is felt throughout an area of 7000 miles across. Lastly, the winds which circulate about the Sonth Pole are more beavily charged with moisture than are the winds of corresponding parts of the other hemisphere. Now, the extreme degree in which these three conditions- of a perpetual grand cyclone, a moist atmosphere, and a low barometer-co-operate without the Antarctic, ought to produce, within it, an exceptional meteorological stace, and the point to be determined is what that condition may be. Maury maintained that the conjunction will make the climate of the South Polar area milder than that of the north. His theory is that the saturated winds being drawn up to great heights within the Antarctic must then be eased of their moisture, and that simultaneously they must disengage vast quantities of iatent heat; and it is because more heat must be liberated in this manner in the South Polar regions than in the north that he infers a less severe climate for the Antarctic. He estimates that the resultant relative differences between the two polar climates will be greater than that between a Canadian and an English winter (Maury's " Meteorology," p. 466). Ross reports that the South Polar summer is rather colder than that of the north, but still the southern winter may be less ex treme, and so the mean temperature may be higher. If we examine the weather reports logged by Antarctic voyagers, instead of the temperature merely, the advantage still seems to rest with the south. In the first place, when the voyager enters the Antarctic, he sails out of a tempestuous zone into one of calns. To demonstrate the truth of this statement, I have made an atstract of Ross's log for the two months of January and February 184r, which he spent within the Antarctic circle. To enable everyone to understand it, it may be well to explain that the wind force is registered in figures from $o$, which stands for a dead calm, up to I2, which represents a hurricane. I find that during these 60 days it never once blew with the force $8-$ that is, a fresh gale; only twice did it blow force 7 , and then only for half a day each time. Force 5 to 6 -fresh to strong breezes-is logged on $2 \mathrm{I}$ days. Force I to 3 -that is, gentle breezes-prevailed on 34 days. The mean wind force registered under the entire 60 days was $3 \% 43$-that is, only a four to five knot breeze. On 38 days, blue sky was logged. They never had a single fog, and on II lays only was it even misty. On the other hand, snow fell almost every second day. We find such entries as these- "beautifully clear weather," and "atmosphere so extraordinarily clear that Mount Herschel, distant 90 miles, looked only 30 miles distant." And again, "Iand seen I 20 miles distant, sky beautifully clear." Nor was this season exceptional, so far as we can tell, for Dr. M'Cormack, of the Erelus, in the third year of the voyage, and after they had lefi the Antarctic for the third and last time, enters in his diary the following remark. He says: "It is a curious thing that we have always met with the finest weather within the Antarctic circle ; clear, cloudless sky, bright sun, light wind, and a long swell" (M'Cormack's "Antarctic Voyage," vol. i. p. 345). It would seem as if the stormy westerlies, so familiar to all Australian visitors, had given to the whole southern hemisphere a name for bad weather, which, as yet at least, has not been earned by the South Polar regions. It is probable, too, that the almost continuous gloom and fog of the Arctic (Scoresby's "Arctic Regions," pp. 97 and I37) July and August have prejudiced seamen against the Antarctic summer. The true character of the climate of this region is one of the problems awaiting solution. Whatever its nature may be, the area is so large and so near to us that its meteorology must have a dominaut influence on the climate of Australia, and on this fact the value of a knowledge of the weather of these parts must rest.

To turn to another branch of science, there are several questions relating to the earth's magnetism which require for their solution long-maintained and continuous observations within the Antarctic circle. The mean or permanent distributiun of the world's magnetism is believed to depend upon causes acting in the interior of the earth, while the periodic variations of the needle probably arise from the superficial and subordinate currents produced by the daily and yearly variations in the temperature of the earth's surface. Other variations occur at irregular intervals, and these are supposed to be due to atmospheric electricity. All these different currents are excessively frequent and powerful about the poles, and a sufficient series of observations might enable physicists to differentiate the various kinds of currents, and to trace them to their several sources, whether internal, superficial, or meteoric. To do this properly at least one land observatory should be established for a period. In it the variation, dip, and intensity of the magnetic currents, as well as the momentary fluctuations, of these elements, would all be recorded. Fixed term days would be agreed on with the observatories of Australia, of the Cape, America, and Europe, and during these terms a concerted continuous watch would be kept up all round the globe to determine which vibrations were local and which general.

The present exact position of the principal south magnetic pole has also to be fixed, and data to be obtained from which to calculate the rate of changes in the future, and the same may be said of the foci of magnetic intensity and their movements. In relation to this part of the subject, Captain Creak recently reported to the British Association his conclusions in the following terms. He says :- "Great advantage to the science of 
terrestrial magnetism would be derived from a new magnetic survey of the southern hemisphere extending from the parallel of $40^{\circ} \mathrm{S}$. as far towards the geographical pole as possible."

Intimately connected with terrestrial magnetism are the phenomena of auroras. Their nature is very obscure, but quite recently a distinct advance has been made towards discovering some of the laws which regulate them. Thanks to the labours of Dr. Sophus Tromholt, who has spent a year within the Arctic circle studying them, we now know that their movements are not as eccentric as they have hitherto appeared to be. $\mathrm{He}$ tells us that the Aurora Borealis, with its crown of many lights, encircles the Pole obliquely, and that it has its lower edge suspended above the earth at a height of from 50 to I0o miles, the mean of 18 trigonometrical measurements, taken with a base line of 50 miles, being 75 miles. The aurora forms a ring round the Pole which changes its latitude four times a year. At the equinoxes it attains its greatest distance from the Pole, and at midsummer and midwinter it approaches it most closely, and it has a zone of maximum intensity which is placed obliquely between the parallels of $60^{\circ}$ and $70^{\circ} \mathrm{N}$. The length of its meridional excursion varies from year to year, decreasing and increasing through tolerably regular periods, and reaching a maximum about every eleven years, when, also, its appearance simultaneously attains to its greatest brilliancy. Again, it has its regular yearly and daily movements or periods. At the winter solstice it reaches its maximum annual intensity, and it has its daily maximum at from $8 \mathrm{p} . \mathrm{m}$. and $2 \mathrm{a} . \mathrm{m}$., according to the latitude. Thus at Prague, in lat. $50^{\circ} \mathrm{N}$, , the lights appear at about 8.45 p.m. ; at Upsala, lat. $60^{\circ} \mathrm{N}$., at $9.30 \mathrm{p.m}$. ; at Bossekop, $70^{\circ}$ N., at $1.30 \mathrm{a} . \mathrm{m}$. Now, while these data may be true for the northern hemisphere, it remains to be proved how far they apply to the southern. Indeed, seeing that the atmosphere of the latter region is moister and shallower than that of the former, it is probable that the phenomena would be modified. A systematic observation of the Aurora Australis at a number of stations in high latitudes is therefore desirable.

Whether or not there is any connection between auroral exhibitions and the weather is a disputed point. Tromholt believes that such a relationship is probable " Under the Rays," 1283). He says that, "however clear the sky, it always became overcast immediately after a vivid exhibition, and it generally cleared again as quickly" ("Under the Rays," I235). Payer declares that brilliant auroras were generally succeeded by bad weather ("Voyage of Tegelhoff," I324), but that those which had a low altitude and little mobility appeared to precede calms. Ross remarks of a particular display "that it was followed by a fall of snow, as usual " ("Ross's Voyage," 1312). Scoresby appears to have formed the opinion that there is a relationship indicated by his experience. It is, therefore, allowable to regard the ultimate establishment of some connection between these two phenomena as a possible contingency. If, then, we look at the eleven-year cycle of auroral intensity from the meteorological point of view, it assumes a new interest, for these periods may coincide with the cycles of wet and dry seasons, which some meteorologists have deduced from the records of our Australian climate, and the culmination of the one might be related to some equivalent change in the other. For if a solitary auroral display be followed by a lowered sky, surely a period of continuous auroras might give rise to a period of continuous cloudy weather, with rain and snow. Fritz considers that he has established this eleven-year cycle upon the strength of auroral records extending from 1583 to 1874 , and his deductions have been verified by others.

In January I 886 we had a wide-spread and heavy rainfall, and also an auroral display seen only at Hobart, but which was sufficiently powerful to totally suspend communication over all the telegraph lines situated between Tasmania and the China coast. This sensitiveness upon the part of the electric currents to auroral excitation is not novel, for long experience on the telegraph wires of Scandinavia has shown that there is such a delicate sympathy between them that the electric wires there manifest the same daily and yearly periods of activity as those that mark the auroras. The current that reveals itself in fire in the higher regions of the atmosphere is precisely the same current that plagues the operator in his office. Therefore, in the records of these troublesome earth-currents, now being accumulated at the Observatory by Mr. Ellery, we are collecting valuable data, which may possibly enable the physicist to count the unseen auroras of the Antarctic, to calculate their periods of activity and lethargy, and, again, to check these with our seasons. But it need harcly be said that the observations, which may be NO. IOg4, VOL. 42] made in the higher latitudes and directly under the rays of the Aurora Australis, will have the greater value, because it is only near the zone of maximum auroral intensity that the phenomena are manifested in all their aspects. In this periodicity of the southern aurora I have named the last scientific problem to which I had to direct your attention, and I would point out that if its determination should give to us any clue to the changes in the Australian seasons which would enable us to forecast their mutations in any degree, it would give to us, in conducting those great interests of the country which depend for their success upon the annual rainfall, an advantage which would be worth, many times over, all the cost of the expeditions necessary to establish it.

Finally, there is a commercial object to be served by Antarctic exploration, and it is to be found in the establishment of a whaling trade between this region and Australia. The price of whalebone has now risen to the large sum of $f_{2000}$ a ton, which adds greatly to the possibilities of securing to the whalers a profitable return. Sir James Ross and his officers have left it on record that the whale of commerce was seen by them in these seas, beyond the possibility of a mistake. They have stated that the animals were large, and very tame, and that they could have been caught in large numbers. Within the last few years whales have been getting very scarce in the Arctic, and in consequence of this two of the most successful of the whaling masters of the present day, Captains David and John Gray, of Peterhead, Scotland, have devoted some labour to collecting all the data relating to this question, and they have consulted such survivors of Ross's expedition as are still available. They have published the results of their investigations in a pamphlet, in which they urge the establishment of the fishery strongly, and they state their conclusions in the following words. They say:- "We think it is established beyond doubt that whales of a species similar to the right or Greenland whale, found in high northern latitudes, exist in great numbers in the Antarctic seas, and that the establishment of a whale fishery within that area would be attended with successful and profitable results." It is not necessary for me to add anything to the opinion of such experts in the business. All I desire to say is that if such a fishery were created, with its head-quarters in Melbourne, it would probably be a material addition to our prosperity, and it would soon increase our population by causing the families of the hardy seamen who would man the fleet to remove from their homes in Shetland and Orkney and the Scotch coasts, and settle here.

In conclusion, I venture to submit that I have been able to point to good and substantial objects, both scientific and commercial, to justify a renewal of Antarctic research, and I feel assured that nothing could bring to us greater distinction in the eyes of the whole civilized world than such an expedition, judiciously planned and skilfully carried out.

\section{QUARTZ FIBRES.'}

BEFORE I enter upon the subject upon which $I$ have to address you, I wish to point out that, quite apart from any deficiency on my part which will be only too apparent in the course of the evening, it is my intention to commit two faults which may well be considered unpardonable. In the first place, I shall speak entirely about my own experiments, even though I know that the iteration of the first personal pronoun for the space of one hour is apt to be as monotonous to an audience as it is wanting in taste on the part of a lecturer. In the second place, I am going almost to depend upon the motions of a spot of light to illustrate the actions which I shall have to describe, in spite of the fact that it is impossible for an audience to get up any enthusiasm when watching the wandering motion of a spot of light the result of the manipulation of a mystery-box, of which it is impossible to see the inside. These, however, are faults which are the immediate consequence of the nature of my subject.

Physicists deal very largely with the measurement of extremely minute forces, which it is of the utmost importance that they should be able to measure accurately. Now forces may be considered under two aspects. It may be that the force which is developed and which has to be measured is a twist, in which case the twisting force may be applied to the end of a wire directly, when the amount through which that wire is twisted is a measure of the twisting force. Or the force may be a direct pull

I Lecture delivered by Prof. C. Vernon Boys, F.R.S., on September 8, 189o, at the Leeds meeting of the British Association. 